\title{
ANTHROPOMETRICAL AND SPORT CONSTITUTIONAL COMPARISON OF GERMAN MALE SOCCER PLAYERS AND MALE STUDENTS OF SPORTS SCIENCES
}

\author{
Cengiz Dogan \& Christoph Raschka \\ Institute of Sports Science, \\ Julius Maximilians University, Germany
}

\begin{abstract}
The aim of the present study was to figure out differences between the body compositions of German soccer players and the students of sports sciences from Hessen (Germany). For this purpose 30 soccer players and 40 sports students were anthropometrically examined. The collective of the students majoring in physical education had the function as a reference group.

Both groups were divided into "experienced" and "less experienced" athletes. The soccer players were recruited from two different Hessian leagues, the players from the higher league were classified as "experienced" athletes and the players of the lower league were defined as "less experienced" football players. The reference group of sports students was also separated into "experienced" and "less experienced" groups. The participants who did workout for more than 10 hours a week, were categorized as "experienced" and the athletes who trained less than 10 hours a week were recorded as "less experienced". In general the students of sports sciences were involved in different sports like ball sports, martial arts, athletics and strengths events.

The measurements were taken under standardised conditions by the authors of this work and the results were analysed statistically (ANOVA). To analyse differences the skin fold measures, the BodyMass-Index (BMI) and the AKS- Index (Lean-Body-Mass) were used. The comparison of the groups is based on the methods of German and Anglo-American schools of constitutional biology. The exact defined landmarks after Conrad, Knussmann, Parnell and Heath \& Carter were
\end{abstract}


used to calculate the body constitution of the different groups and athletes.

The soccer players of the present study had an average body height of $178.8 \mathrm{~cm}+/-6.0 \mathrm{~cm}$ and an average body weight of $71.9 \mathrm{~kg}$. In comparison to the soccer players, the athletes of the reference group are taller and heavier. The average height of the students of sports sciences was $183 \mathrm{~cm}+/-5.1 \mathrm{~cm}$ and they had an average weight of $80.2 \mathrm{~kg}$. Nearly all the height and longitudinal dimensions of the reference group were significantly higher than in the group of soccer players. Depending on the performance level of both groups, there were no significant differences found.

Key words: soccer players, sportstudents, anthropometric measurements, constitutional body types.

\section{INTRODUCTION}

The first soccer like games were played 2,500 years ago. There were different types of games in which the participants tried to take a ball to the opponent's goal. These games were played without exact defined rules and did not have much in common with the modern way of soccer that is known from today.

The modern style of football was established in England in 1863 and developed rapidly in Europe. Over 40 years later the World Football Federation FIFA was founded. The primary responsibility of the FIFA was to develop international rules and regulations and to organize international matches.

Today soccer or football is the most common and famous of sports in the world. Maybe the simple rules and the easy way of playing this game is one of the main reasons why many people from different cultures and countries like to watch and to play soccer. Above all soccer developed into a big industrial sector and has a high value for the economic system of sports. Based on that, the importance of success is more and more in focus, only teams and players who are successful, are able to become famous and earn money. From that point of view, the classification of talent is really important and can help to get success.

The body constitution of soccer players can be a fundamental part of talent. Anthropometric studies can have a key role in talent searching and scouting for soccer and other sports. On closer examination, one of 
the main questions of anthropometric researches is if there are special body constitutions or anthropometric sizes and variables for professional and successful soccer players. It is not only the research for a potential "optimum" body composition of soccer players. The focus of interest is as well on constitutional differences of soccer players from different performance levels.

From Knussmann's [6] point of view, the constitution of the human being can have an effect to general and specific sports skills. Furthermore his idea is that sports have an influence on the shape of the human body.

The present study tries to clarify the mentioned questions by focusing on soccer players and the students of sports sciences as a reference group. Therefore variable anthropometric measurements like height-, girth-, breadth - and body fat-measurements were collected as well as the German constitution typologies according to Conrad \& Knussmann and the Anglo-American Somatotypes appropriate to Parnell and Heath \& Carter were evaluated. Apart from that, the BodyMass-Index and the AKS-Index (Lean-body-mass) were examined.

\section{PARTICIPANTS AND METHODS}

In this study 30 soccer players and 40 students of sports sciences as a reference group were examined. Each proband participated voluntarily and the data were used anonymously. Both groups were divided into "experienced" and "less experienced" athletes; 13 soccer players were recruited from the $5^{\text {th }}$ German Soccer Division and were classified as an "experienced" group. The other 17 soccer players were playing in the $6^{\text {th }}$ German Soccer Division and were rated as "less experienced". The ages of the soccer athletes ranged from 16 for the youngest participant to 23 years for the oldest soccer player.

The reference group is composed of 40 sports students. They were recruited from the Frankfurt Goethe University. Students of physical education have to pass different physical tests during their study and they have to be physically strong and well trained. In general the students of sports sciences were involved in different sports like ball sports, martial arts, athletics and strengths events. Collectively 25 students were classified as "experienced" who did workouts for more than 10 hours a week. In addition to that, 15 students of sports sciences 
were defined as "less experienced", because of their lower training volume of under 10 hours a week. The training volume of the students was determined with interviews. The youngest participant of the reference group was 21 years old and the oldest student had an age of 37 years.

The anthropometrical measurements took place under standardized conditions, to exclude sources of error as much as possible. The heights and lengths were measured with an anthropometer, the breadths and widths with a pelvimeter, the circumferences with a measuring tape. The skin folds, which are important for the calculation of the body fat and also for some constitution typologies, were measured with a caliper. The body weight was measured with a digital scale of the brand Korona. The measurements were evaluated by the author of this study with always the same instruments and conditions. The statistical data were checked and analyzed using ANOVA. Furthermore the age of the participants, the training volume were interviewed and recorded.

The exact defined landmarks after Conrad, Knussmann, Parnell and Heath \& Carter were conducted as the foundation of the examined and calculated measures. In addition to the mentioned constitutional typologies, the BMI (Body-Mass-Index) and the AKS-Index (Lean-BodyMass-Index) were ascertained and calculated.

\section{RESULTS}

The results of the anthropometric data of all examined groups are summarized in Table 1. The students of sports sciences are taller and heavier than the soccer players. They seem to be more muscular, which is proofed by the higher AKS-Index results, but at the same time the body fat percentage is also higher. There were also significant differences of the circumferences. The reference group has the bigger girth results at the upper body and upper extremities. The additional parameters of the widths and the results of the single determinations of the constitution typologies also support the fact that the sports students are on average taller, bigger and heavier than the soccer players of this study.

With the main focus on the experience and performance level of the participants, the variations are less clear. There is a meaningful difference at the sitting height of the participants. In both groups the experienced athletes had significant higher sitting heights. Other 
significant differences with the main focus on the experience are: min. forearm, girth of foot and width of humerus. In all the mentioned body parts, the experienced athletes showed higher values.

All the groups have on average a normal weight, which is demonstrated by the Body-Mass-Index (BMI) results. A normal weight is defined between a BMI of $18.5-24.9 \mathrm{~kg} / \mathrm{m}^{2}$. The group of the soccer players had a mean BMI of $22.4 \mathrm{~kg} / \mathrm{m}^{2}$ and the group of sports students demonstrated a BMI of $24.5 \mathrm{~kg} / \mathrm{m}^{2}$, which is significantly higher. The AKS-Index-Diagram is illustrated in Figure 1 and shows the relationship between the active body substance (musculature) and the body height. The sports students demonstrated higher AKS-Index findings in comparison to the soccer players, but the difference was not significant. These results underline the fact that the students of sports sciences seem to be heavier and more muscular than the soccer players.

According to the German constitution typology after Conrad, the soccer players are on average leptomorph-hyperplastic and there were no meaningful differences found between "experienced" and "less experienced" soccer players. The group of sports students has a metromorph-hyperplastic body type. Based on the experience level, there were no significant differences found. The classification of pyknomorphy and makrosomia after Knussmann orders both groups to leptomorph- makrosom type. The sports students showed significantly higher Makrosomia- results compared to the soccer players.

Regarding to the somatocharts after Parnell and Heath \& Carter, the soccer players are almost all in the mesomorphic area. With this result on the main focus the soccer players of the present study showed an athletic and sporty body constitution. With respect to the experience level of the soccer players, there were no important differences observed.

The group of sports students showed a bigger spreading at the somatocharts after Parnell and Heath \& Carter. Most of the participants of the reference group are mesomorphic, but some are located in the endomorphic area. There were no meaningful differences between experienced and less experienced sports students found. Figures 4 and 5 show the averages in the somatocharts after Parnell and Heath \& Carter. 
Table 1. Results of the body composition data of all the tested groups

\begin{tabular}{|l|c|c|c|c|}
\hline & $\begin{array}{c}\text { soccer players } \\
\text { (experienced) }\end{array}$ & $\begin{array}{c}\text { soccer players } \\
\text { (less } \\
\text { experienced) }\end{array}$ & $\begin{array}{c}\text { sports } \\
\text { students } \\
\text { (experienced) }\end{array}$ & $\begin{array}{c}\text { Sports Stu- } \\
\text { dents (less } \\
\text { experienced) }\end{array}$ \\
\hline n & 13 & 17 & 25 & 15 \\
\hline age (yrs) & $18.2+/-2.3$ & $17.1+/-0.6$ & $23.3+/-3.6$ & $25,4+/-3,5$ \\
\hline height (cm) & $179.4+/-6.3$ & $178.3+/-6.0$ & $184.1+/-4.6$ & $181,2+/-5,5$ \\
\hline $\begin{array}{l}\text { sitting height } \\
\text { (cm) }\end{array}$ & $94.2+/-2.6$ & $92+/-3.6$ & $95.2+/-2.8$ & $92,8+/-4,6$ \\
\hline mass (kg) & $74+/-3.1$ & $70.2+/-2.9$ & $79.7+/-3.2$ & $80,9+/-3,4$ \\
\hline $\begin{array}{l}\text { AKS } \\
\left(\mathbf{A K S} / \mathbf{h}^{\mathbf{3}}\right)\end{array}$ & $1.09+/-0.1$ & $1.08+/-0.1$ & $1.1+/-0.0$ & $1,11+/-0,1$ \\
\hline BMI (kg/m $\left.\mathbf{m}^{\mathbf{2}}\right)$ & $23+/-1.6$ & $22+/-2.6$ & $24.4+/-2.1$ & $24,6+/-2,3$ \\
\hline
\end{tabular}

Table 2. Results of skinfold measurements of all groups

\begin{tabular}{|l|l|c|c|c|c|c|c|}
\hline \multirow{2}{*}{ group } & experience level & $\begin{array}{c}\text { triceps } \\
(\mathrm{mm})\end{array}$ & $\begin{array}{c}\text { fo- } \\
\text { rearm } \\
(\mathrm{mm})\end{array}$ & $\begin{array}{c}\text { suprai- } \\
\text { liacal } \\
(\mathrm{mm})\end{array}$ & $\begin{array}{c}\text { scapula } \\
(\mathrm{mm})\end{array}$ & $\begin{array}{c}\text { thigh } \\
(\mathrm{mm})\end{array}$ & $\begin{array}{c}\text { calf } \\
(\mathrm{mm})\end{array}$ \\
\hline \multirow{2}{*}{$\begin{array}{l}\text { soccer } \\
\text { players }\end{array}$} & experienced & 9.5 & 5.1 & 16.3 & 11.7 & 14.8 & 11.4 \\
\cline { 2 - 9 } & less experienced & 8.8 & 4.2 & 15.2 & 9.2 & 10.7 & 9.1 \\
\cline { 2 - 9 } $\begin{array}{l}\text { sports } \\
\text { stu- } \\
\text { dents }\end{array}$ & complete group & 9.1 & 4.6 & 15.7 & 10.3 & 12.5 & 10.1 \\
\cline { 2 - 9 } & experienced & 10.8 & 5.6 & 20.3 & 14.7 & 13.9 & 11.2 \\
\cline { 2 - 9 } & complete group & 11.3 & 5.8 & 23.2 & 14.9 & 14.5 & 11.9 \\
\hline
\end{tabular}




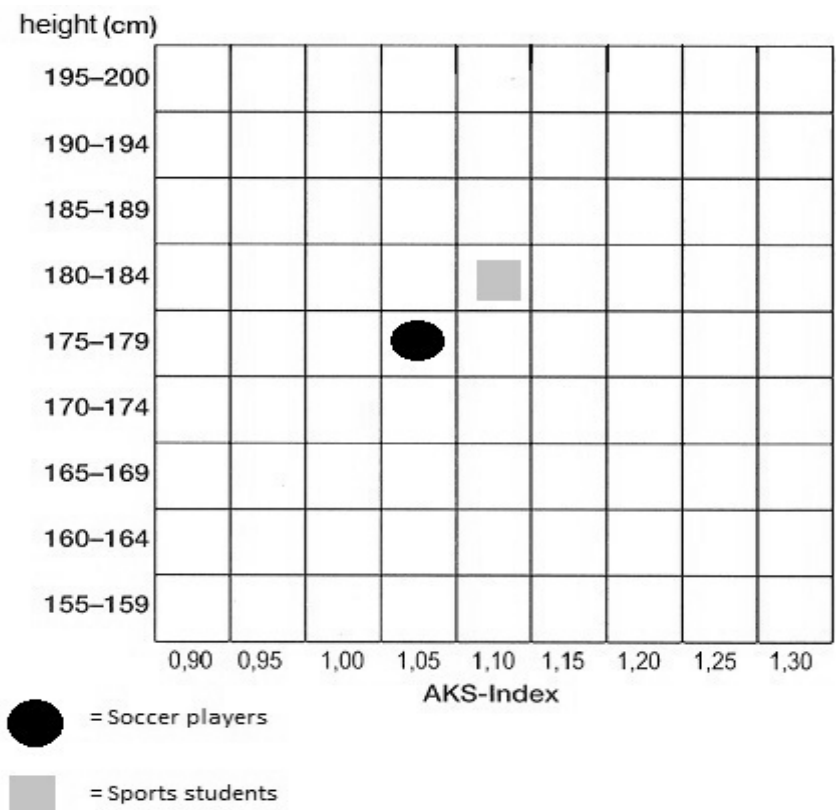

Figure 1. AKS-Index-Diagram with the averages of both groups (No significant differences between the experience level found). 


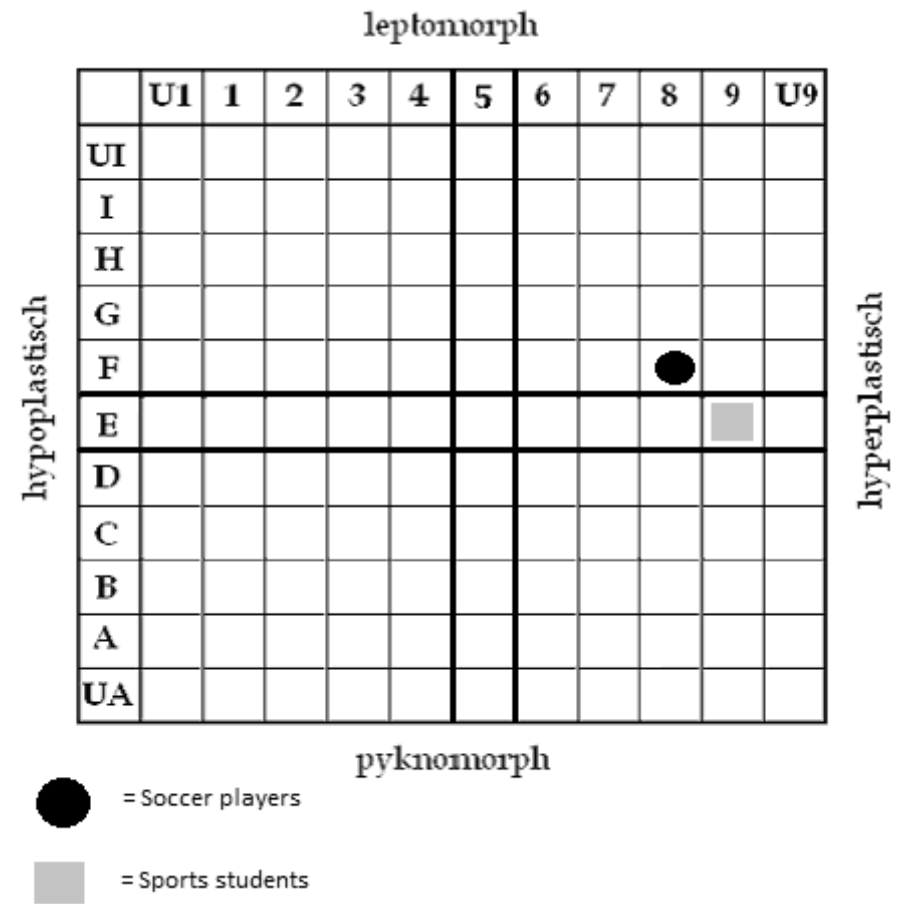

Figure 2. Chessboard pattern graphic after Conrad with the averages of both groups (No significant differences between the experience level found). 


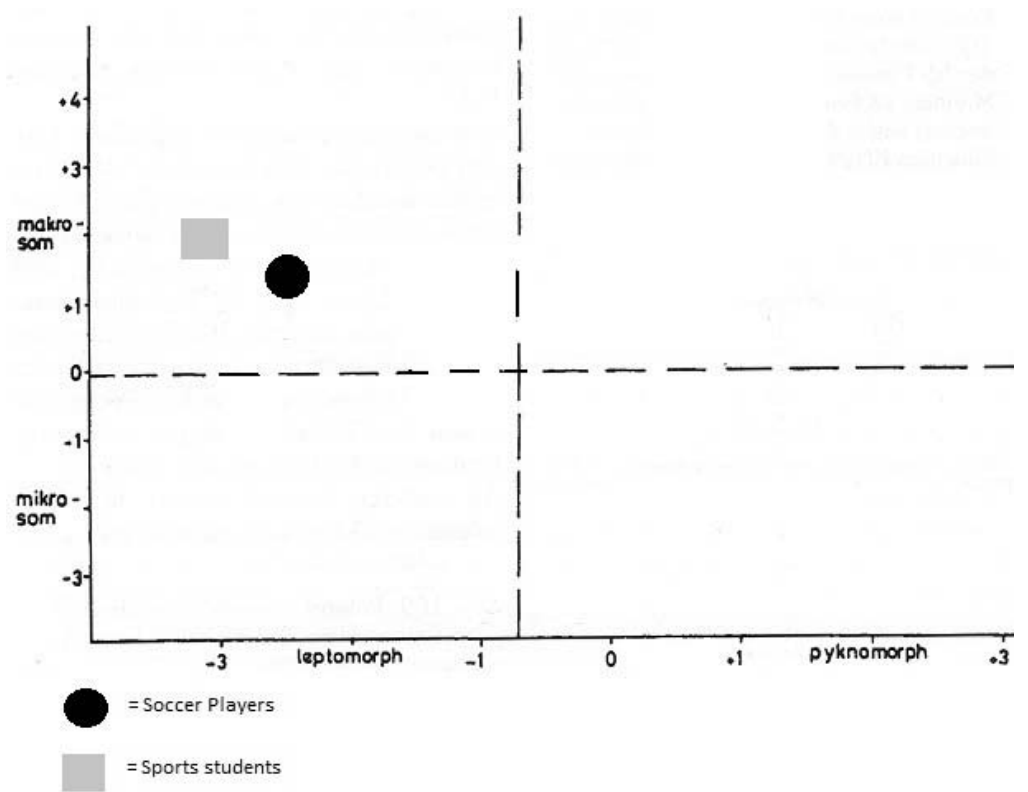

Figure 3. Graphic of constitution types after Knussmann with the averages of both groups. (No significant differences between the experience level found). 


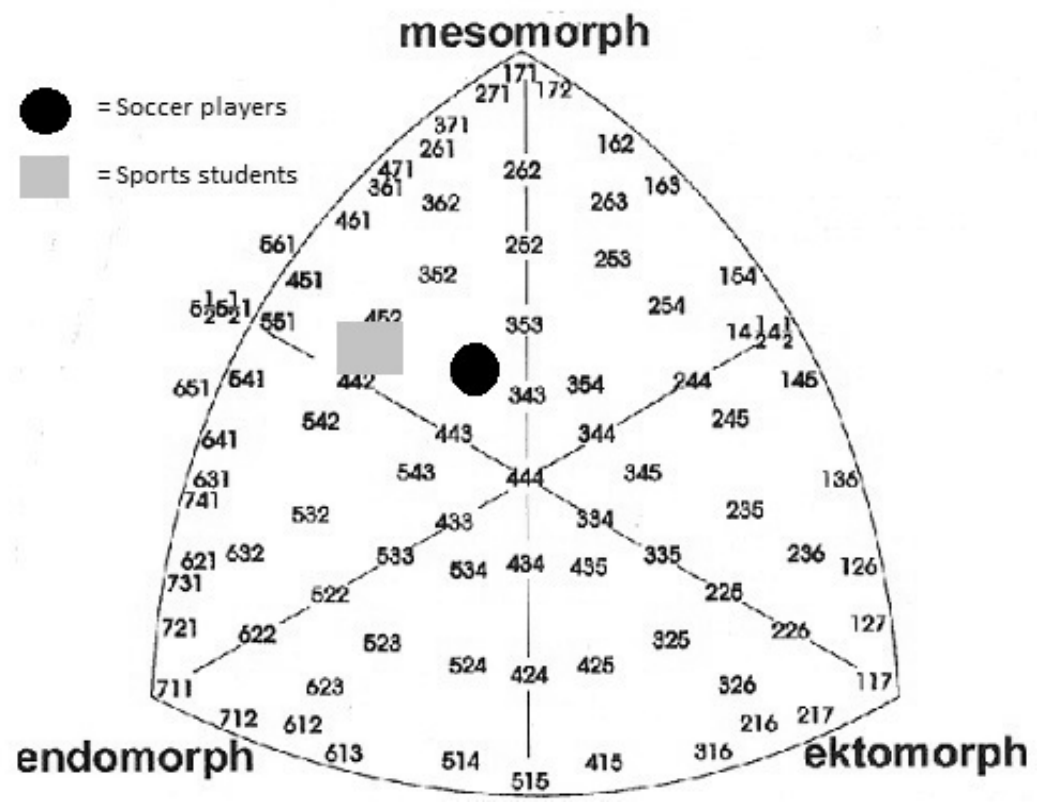

Figure 4. Somatochart after Parnell with the averages of both participant groups (No significant differences between the experience level found). 


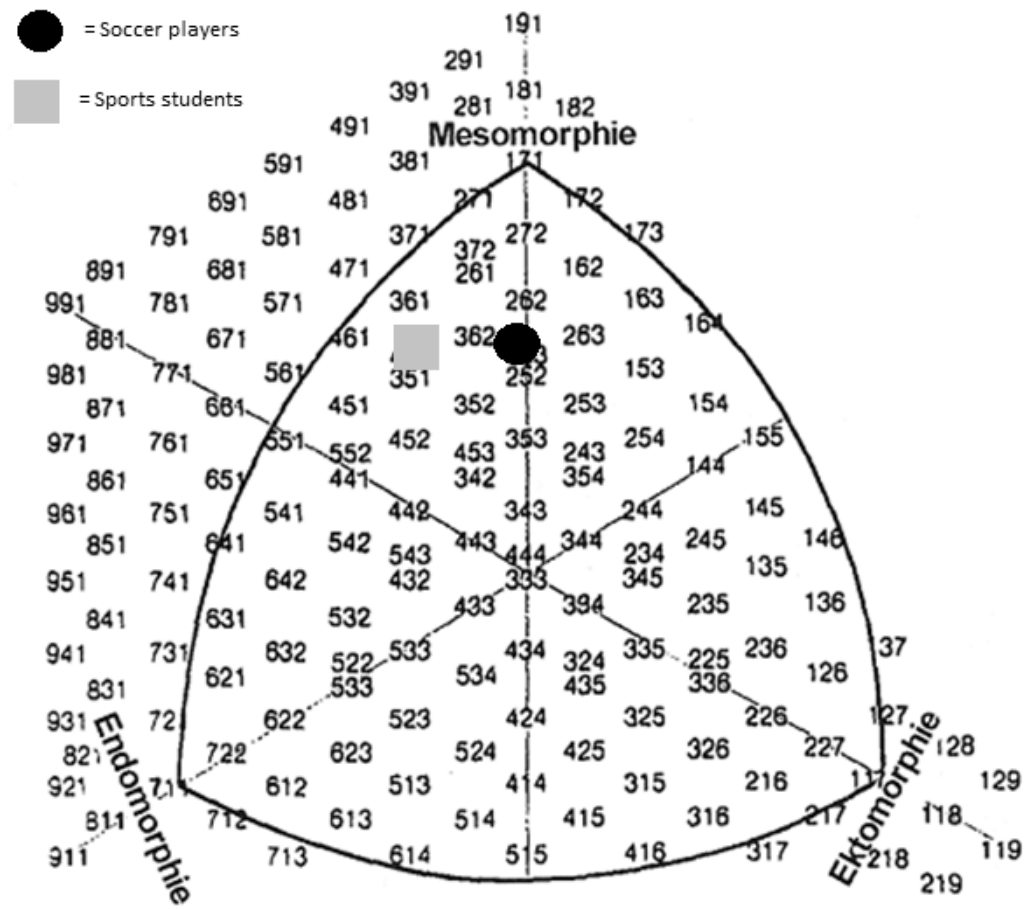

Figure 5. Somatochart after Heath \& Carter with the averages of both participant groups (No significant differences between the experience level found).

\section{DISCUSSION}

The present study supports the conclusion of a clear difference between the anthropometrically examined soccer players and the students of sports sciences, according to the collected data.

The group of the soccer players demonstrates an average height of $178.8 \mathrm{~cm}$ comparing to the group of sports students, who have an average height of $183.0 \mathrm{~cm}$. The participants of the reference group are clearly taller than the soccer players of this study. According to the experience level, the experienced athletes are taller than the less experienced sportsmen, but the difference is not significant. Corresponding to the Federal Office of Statistics the average height for 18 to 40 
year old men in Germany is about $178 \mathrm{~cm}$. In comparison to the findings of the present study, the soccer players are almost at the national average and the sports students are $5 \mathrm{~cm}$ over the above the nationwide average. In addition, another interesting fact is that the experienced athletes had significant higher sitting heights than the less experienced participants.

The reference group of sports students illustrate an average body weight of $80.2 \mathrm{~kg}$. They are heavier than the group of soccer players who present an average weight of $71.9 \mathrm{~kg}$. They have also higher AKSIndex results, which is a proof of a more muscular mass. After Matkovic et al. [9] and Luiz do Prado et al. [7], who examined professional soccer players, an AKS-Index around $1.13 \mathrm{AKS} / \mathrm{h}^{3}$ is meaningful for professional soccer players $[7 ; 9]$. The soccer players from the present study, who play in lower divisions than the probands of Matkovic et al. and Luiz do Prado et al. show lower AKS-Index results. The mentioned findings illustrate a higher muscle mass of professional soccer players in comparison to the soccer players of this study. The professional players seem to be more athletically trained.

Other interesting findings are the lower body-fat values of the soccer players. All the skin fold results of the soccer players are lower than the findings of the reference groups. A soccer player has to be quick and fast to be a successful player. With this fact in mind, a high body-fat percentage could have a negative influence on the conditional aspects and the overall performance of a soccer player. In conclusion a low body-fat percentage could be important for an optimum performance of a soccer player. According to the performance level of the soccer players in the present study, there are no meaningful differences found.

The reference group of sports students has significantly bigger circumferences at the upper body and the upper extremities. A possible explanation for this result could be the training of the sports students, who are involved in different sports like athletics and strengths events. This contains more strength training than the training of soccer players who are more focused on technical and tactical training and on other conditional aspects. Another interesting result is the girth of the lower extremities as thigh and calf, because there is no significant difference between the soccer players and the sports students. This result shows the strong and muscular legs of the soccer players, although the students majoring in physical education have the higher weight and higher body- 
fat. The soccer players have on average a significant smaller waist girth than the reference group, which is correlating with the lower skin fold results at this area. After Raschka a small waist in combination with a big shoulder breath is described as an "athletic shape" [10].

Corresponding to the results of the breaths, the sports students have on average the higher values. Nearly all breaths are significantly higher in comparison to the group of soccer players. The mentioned results highlight the stronger bone structure of the sports students. There are no meaningful differences found according to the experience level of the participants.

Regarding to the constitution theory of Conrad, the soccer players are on average leptomorph-hyperplastic. The group of sports students has a metromorph-hyperplastic body constitution. Based on the experience level, in both groups there were no significant differences found. Knussmann has the view that the leptomorph body type is suitable for a jumper and a runner, because of a low relative body weight, which is an advantage on locomotion [5]. Both mentioned aspects (jumping and running) are important aspects of soccer. The classification of pyknomorphy and makrosomia after Knussmann orders both groups to the leptomorph- makrosom type. The students of sports sciences have significantly higher Makrosomia- results.

Referring to Parnell and Heath \& Carter both groups are on average in the mesomorphic area. The students of sports sciences have on average higher endomorphic values. This result means that they are more massive than the soccer players, which is proofed by the higher skin fold- results and the higher AKS-Index findings. The separation of the participants in experienced and less experienced sportsmen does not show any significant differences.

Summarizing both groups of this study has a sporty physique which is shown by the high mesomorphic values after Parnell and Heath \& Carter. The sports students are taller and heavier than the soccer players, but the data of the soccer players contain lower skin fold measurement results, which illustrates a lower body- fat.

The hypothesis that there is a significant difference between the body constitution of soccer players and sports students, could be proofed in the present study. There were not any meaningful differences between the experience-level of the participants, however. 


\section{REFERENCES}

1. Bernhard, W. \& Jung, K. (1998). Sportanthropologie. Fragestellungen, Methoden und Ergebnisse am Beispiel der Laufdisziplinen und des alpinen Skirennsportes. Stuttgart: Gustav Fischer Verlag

2. Carter, J. (1984). Somatotypes of Olympic athletes from 1948 - 1976. Medicine and Sports Science, Vol. 18, pp 80-109.

3. Conrad, K. (1963). Der Konstitutionstypus. Berlin, Göttingen, Heidelberg: Springer Verlag

4. Christiane, E. \& Lanfranchi, P. (2006): Football History: International Perspectives / Fußball-Geschichte: Internationale Perspektiven. Historische Sozialforschung, HSR Vol. 31, 2006, Göttingen

5. Knußmann, R. (1980). Vergleichende Biologie des Menschen. 1. Auflage. Stuttgart: Gustav Fischer

6. Knußmann R. (1996). Vergleichende Biologie des Menschen. Lehrbuch der Anthropologie und Humangenetik, Stuttgart, Gustav Fischer Verlag, 2. Auflage

7. Luiz do Prado, W., Botero, J.P., Fernandes, R.L., Rodrigues C.L., Cuvello, L., Dâmaso, A.R. (2006). Anthropometric profile and macronutrient intake in professional Brazilian soccer players according to their field positioning. Sociedade Brasileira de Medicina do Esporte, pp 52-55, Barsillien,

8. Martin, R. \& Knußmann, R. (Hg.). (1988). Anthropologie. Handbuch der vergleichenden Biologie des Menschen. Stuttgart, New York: Gustav Fischer Verlag

9. Matkovic, R., Misigoj-Durakovic, M., Matkovic, B., Jankovic, S., Ruzic L., Leko, G., Kondric, M. (2003). Morphological differences of elite Croatian soccer players according to the team position. University of Zagreb: Zagreb

10. Raschka, C. (2006). Sportanthropologie. Köln: Sportverlag Strauß

11. Statistisches Bundesamt (2009) Mikrozensus 2009- Körpermaße der Bevölkerung. Wiesbaden, http://www.destatis.de (access on January $\left.12^{\text {th }} 2010\right)$

12. Tittel, K. \& Wutscherk, H. (1972). Sportanthropometrie: Aufgaben, Bedeutung, Methodik und Ergebnisse biotypologischer Erhebungen. Leipzig: Barth Verlag

13. Wutscherk H. (1981). Grundlagen der Sportanthropometrie. Deutsche Hochschule für Körperkultur. Leipzig 
92 C. Dogan, C. Raschka

Adress for correspondence:

Cengiz Dogan

Julius Maximilians University

Institute of Sports Science

Beethovenstr.97, 63263 Neu-Isenburg, Germany

E-mail: Cdogan1@gmx.de 